\title{
Endogenous retroviruses and multiple sclerosis- new pieces to the puzzle
}

\author{
Kari K Nissen ${ }^{1}$, Magdalena J Laska ${ }^{1}$, Bettina Hansen ${ }^{1}$, Thorkild Terkelsen ${ }^{1}$, Palle Villesen², Shervin Bahrami ${ }^{3}$, \\ Thor Petersen ${ }^{4}$, Finn S Pedersen ${ }^{5}$ and Bjørn A Nexø ${ }^{1 *}$
}

\begin{abstract}
The possibility that retroviruses play a role in multiple sclerosis (MS) has long been considered; accumulating findings suggest this to be most likely in the form of human endogenous retroviruses (HERVs). A genetic test series of fifty endogenous retroviral loci for association with MS in Danes showed SNP markers near a specific endogenous retroviral locus, HERV-Fcl located on the X-chromosome, to be positive. Bout Onset MS was associated with the HERV-Fc1 locus, while a rarer form, Primary Progressive MS, was not. Moreover, HERV-Fc1 Gag RNA in plasma was increased 4-fold in patients with recent history of attacks, relative to patients in a stable state and to healthy controls.

Finally, genetic variations in restriction genes for retroviruses influence the risk of MS, providing further support for a role of retroviral elements in disease.

We speculate that endogenous retroviruses may activate the innate immune system in a variety of ways, involving the host proteins, TRIMs, TLRs, TREXs and STING. Observations in HIV-positive patients suggest that antiretroviral drugs can curb MS. Thus, these new findings regarding the etiology and pathogenesis of MS, suggest alternative ways to challenge autoimmune diseases.
\end{abstract}

Keywords: Multiple sclerosis, Endogenous retroviruses, HERV-FC1, TRIM, BST2, Genetic association

\section{Review}

Multiple sclerosis (MS) is a chronic inflammatory, demyelinating disease of the central nervous system, probably caused by interaction of multiple genes and environmental factors. It is the most common neurological disease causing debilitation in young people in Scandinavia. Disease onset usually occurs in young adults, and it is more common in women [1]. It has a prevalence that ranges between 2 and 150 per 100,000 [2]. The ultimate pathogenic effector appears to be the immune system [1]. In most people, MS is initially characterized by sudden bouts of disease, called attacks, alternating with periods of remission. Gradually, the disease may become progressive. There is no known cure for multiple sclerosis and treatments attempt to return function after an attack, prevent new attacks, and prevent disability [1].

\footnotetext{
* Correspondence: nexo@hum-gen.au.dk

${ }^{1}$ Department of Biomedicine, Aarhus University, Wilhelm Meyers Allé 4, DK-8000, Aarhus, C, Denmark

Full list of author information is available at the end of the article
}

MS has a clear genetic component as evidenced by family studies [3,4] and studies of twins [5]. The human leukocyte antigen (HLA) immune gene-cluster is long established as a risk factor [6], and recent genome wide association studies (GWAS) have added numerous susceptibility loci, mainly related to immune regulatory genes, to the list [7]. However, each of these contributes modest effects to the combined risk of MS development, and still leaves genetic risk factors to be identified [8]. Many environmental factors, from sunlight to smoking, have been suggested [9]. Some epidemiological findings could suggest the contribution of infectious agents [10], and especially infection with Epstein-Barr virus seems to predispose to MS later in life [11]. MS is thus assumed to develop in genetically susceptible individuals after exposure to certain environmental risk factors.

The possibility that retroviruses play a role in the pathogenesis of MS has long been considered [12]. In several animal models (sheep, mice, and monkeys) demyelinating diseases are well known, and can be caused by horizontally transmitted retroviruses [13-15]. A number of retroviruses
C Biomed Central

(c) 2013 Nissen et al.; licensee BioMed Central Ltd. This is an Open Access article distributed under the terms of the Creative Commons Attribution License (http://creativecommons.org/licenses/by/2.0), which permits unrestricted use, distribution, and reproduction in any medium, provided the original work is properly cited. 
have been considered since they have links with similar neurodegenerative disorders, such as HTLV-1, which causes tropical spastic paraparesis in humans [16], and the Visna-Maedi virus, which causes an MS-like disease in sheep [17]. This led to intense search for a retrovirus involved in MS and in 1989 retroviral particles and reverse transcriptase activity was detected in cells from MS patients [18]. Further studies of this MS-associated retrovirus (MSRV) finally established it to be of endogenous origin, forming a new family of HERV-W [19]. Human endogenous retroviruses (HERVs) are remnants of prehistoric exogenous retroviruses, integrated in the human genome during primate evolution through germ line infection.

At present, there is no direct evidence for the involvement of an exogenous retrovirus in MS, but endogenous retroviruses may well be one or more of the genetic factors in the pathogenesis. As will become apparent in the following, we do not see the endogenous retroviruses as alternatives to the immune-mediated damage, but as triggers of it.

Over time, a large number of studies have reported the detection of various HERV-molecules (mainly from HERV-W and HERV-H) and antibodies towards such epitopes more frequently in MS patients, as was recently reviewed by Antony et al. [20]. An intriguing new development has been the report of increased numbers of HERV-W DNA copies in genomic DNA from PBMCs from secondary progressive MS patients, suggesting that HERV-W amplifies in these patients [21].

A potential problem in the implication of HERV-W/ MSRV and HERV-H sequences in MS from the studies described above is the inability to distinguish causation and passenger status through expression experiments. Does the virus contribute to disease or does disease activate the virus? In spite of the importance of these findings, this is a problem that cannot be solved within the frame of expression studies of ubiquitous genomic elements. To get around this obstacle, we initially chose to study the genetics of endogenous retroviral loci, followed by physiological experiments only when the identity of a genetically associated locus was established. As far as is known, the disease cannot alter specific polymorphisms in polyclonal DNA, which is used in these studies. The direction of causality is thus relatively certain to be from DNA to disease; not the reverse.

By means of an approach based on genetic epidemiology, single nucleotide polymorphisms (SNPs) in close proximity of fifty endogenous retroviral loci were tested for statistical association with MS. The fifty loci were chosen because their sequences indicate that between zero and two mutations would enable encoding at least one full length viral protein. Markers near a specific endogenous retroviral locus, HERV-Fc1, located on the human X-chromosome, were found to be associated with disease in a Danish cohort of 350 MS cases and 500 controls [22]. HERV-Fc1 had not previously been related to MS. The association was repeated in one Danish, and in one Norwegian cohort [22,23]. A fourth (Danish) cohort was negative for disease association [22].

Subtypes of MS have also been studied for association with HERV-Fc1. Bout Onset MS, the common forms of MS encompassing Relapsing/Remitting MS and Secondary Progressive MS, was associated with the locus, while another form of MS, Primary Progressive MS, seemed not to be [23]. Interestingly, an independent study has indicated that Primary Progressive MS may be associated with another endogenous retroviral locus at chromosome 7, HERV-16 (SNP rs996343) [24]. In a series of expression studies [25], it was shown that the level of HERV-H/F GAG protein (determined by antibodies targeting but not specific to HERV-Fc1) is increased in PBMCs from MS patients relative to healthy controls. It was also found that the level of protein was elevated in the circulating T-cell compartment in MS patients with a recent history of attacks, relative to patients in a stable state and to healthy controls. Finally, in agreement with this it was found that expression of HERV-Fc1 RNA in plasma was increased 4-fold in patients with a recent history of attacks, relative to patients in a stable state and to healthy controls. Combined with the genetic studies this suggests an active role of HERV-Fc1 in the pathogenesis of MS. A search for extra germ line copies of HERV-Fc1 in MS was unfruitful [26].

Treatment with 5-aza-dC (5-azadeoxycytidine) resulted in demethylation of HERV-Fc1 5'LTR and significantly increased levels (up to 50000 fold) of HERV-Fc1 mRNA expression in cells previously not expressing HERV-Fc1, or with a very low basic expression level [27,28]. This confirms that retroelements are generally epigenetically silenced in somatic cells [29]. Although we have no data as of yet, one could imagine that other physiological mechanisms might also activate expression of HERV products and could contribute to disease.

Another line of inquiry supports the involvement of retrovirus in MS. Genes known to restrict the replication of viruses, namely TRIM5, TRIM22 and BST2, have been shown to influence the risk of MS [22, and Nexø et. al manuscript submitted]. The so-called APOBEC3 genes showed a similar, but statistically insignificant, tendency, while the TREX1 gene seemed inert. These retroviral restriction factors, protecting the host from exogenous retroviral infection, may also recognize products of endogenous proviruses [30-33].

Current models of MS pathogenesis implicate the immune system as the ultimate effector, but combine it with neurodegeneration [34]. How this might be related to the endogenous retroviruses is unknown, but several 
possibilities can be suggested. HERVs in general are defective. However, since some are able to produce proteins they may be able to start an infectious-like process either through complementation or recombination. Thus, it might be the entire endogenous retroviral repertoire that determines infectivity and not the individual locus. If activated, the endogenous viruses could trigger the adaptive immune system or, equally likely, the innate immune system.

The human genome contains several sets of genes encoding dozens of proteins constituting anti-retroviral defense mechanisms. One such set includes the TRIM proteins. TRIM5 protein activation is mediated by the incoming viral capsid. Recently, Jeremy Luban's group reported that TRIM5-binding of the capsid activates signal transduction, stimulating the innate immune system [35]. As described above, markers in and around the TRIM5 gene are associated with the risk of MS [22 and Nexø et al. manuscript submitted]. Thus, it would be interesting to investigate the possibility that HERVs with potential Gag expression, e.g. HERV-Fc1, via TRIM could stimulate the innate immune system.

Alternative mechanisms for the activation of the innate immune system may exist. Un-integrated DNA in the cytosol is known to trigger innate immune signaling [36]. RNA components of internalized viral sequences activate the innate immune system by stimulating Tolllike receptors in the endosomes [37]. The triggering of TLRs by HERVs in MS has previously been proposed [38]. Moreover, triggering of the innate cellular antiviral system by membrane-fusion of nucleic acid devoid virus-like-particles and cell, may act via the adaptor STING [39]. Finally, an entirely different mechanism was described in a recent paper; Dysregulation of the heterochromatin factor HP1 $\alpha$ binding sites was shown to occur in MS. HP1 $\alpha$ was again shown to influence both expression of HERVs and immune factors [40].

Thus, the endogenous viruses are mobile subcellular structures that span the divide between self and foreign. We specifically suggest that HERVs, though now a part of self, to some extent have retained the ability to trigger innate immune sensors of foreign patterns. This in turn could lead to stimulation of an adaptive autoimmune response. A combination of the above mechanisms could conceivably lead to a response, initially elicited by the endogenous viruses, but ultimately reacting to a broad range of cellular components.

Noticeably, none of these models require actual productive infection cycles; a steady supply of virus-like particles performing the initial parts of an infection would be enough. Therefore, our induction experiments, which show that high levels of viral mRNA expression can be achieved from the endogenous loci when cells are exposed to drugs, take on a special significance. However, we sorely miss the identification of normo-physiological mechanisms other than actual replication that can enhance endogenous virus expression to an extent leading to activation of the immune system. Late infection with Epstein Barr Virus (EBV) is associated with MS, and in vitro EBV infection of blood leucocytes and astrocytes leads to activation of HERVs [41]. Maybe, late EBV infection in vivo triggers large scale HERV activation.

Future investigations must substantiate the involvement of HERVs in MS by genetic experiments as well as expression studies. Studies of host factors should serve the same purpose. The activation of the innate immune system by retroviruses and the role of TRIMs, TLRs, TREXs, STING and HP1 $\alpha$ should be elucidated in both genetic and expression studies. The potential interaction between different HERVs is also of considerable interest.

Importantly, recent data suggest that MS is influenced by highly active anti-retroviral treatment (HAART) $[42,43]$. MS is uncommon among HIV-positive HAARTtreated persons (incidence rate ratio $=0.3: 95 \%$ confidence interval $=0.04-2.2$ ). Although the group-size is small, and the results are not statistically significant, the effect is fairly strong and in accordance with the expected trend suggesting that antiretroviral medicines can curb MS. If these findings are substantiated, it becomes imperative to investigate in a clinical trial, if HAART can be effective against MS and possibly other autoimmune diseases. At the moment, a clinical trial for the antiviral drug Raltegravir is in its initial phase, to test if this integrase inhibitor can suppress HERV activity and ameliorate MS progression [44]. A more targeted approach is also on trial, as a monoclonal antibody towards MSRV Env (GNbAC1) is being tested as a remedy for MS [45]. It will be most interesting to follow these innovative treatment strategies.

\section{Conclusion}

Solid evidence points to an involvement of the endogenous retrovirus HERV-Fc1 in the initiation of MS in Scandinavians. Time will show if the more speculative aspects of this review are borne out.

\section{Competing interests}

The authors declare that they have no competing interests.

\section{Authors' contributions}

KKN, MJL, BAN: Ideas, drafting. All other authors: Contributory ideas, discussions, review of the manuscript, literature search. All authors read and approved the final manuscript.

\section{Acknowledgement}

This work was supported by The Lundbeck Foundation, The Jascha Foundation, and The Danish Sclerosis Society. The funding sources had no influence on the acquisition and evaluation of data, write-up, or the decision to publish. 


\section{Author details}

${ }^{1}$ Department of Biomedicine, Aarhus University, Wilhelm Meyers Allé 4, DK-8000, Aarhus, C, Denmark. ²Bioinformatics Research Centre, Aarhus University, C.F.Møllers Allé 8, DK-8000, Aarhus, C, Denmark. ${ }^{3}$ SKAUvaccines, Incuba Science Park, Åbogade 15, DK-8200, Aarhus, N, Denmark. ${ }^{4}$ Department of Neurology, Aarhus University Hospital, Nørrebrogade 44, DK-8000, Aarhus, C, Denmark. ${ }^{5}$ Department of Molecular Biology and Genetics, Aarhus University, C.F.Møllers Allé 3, DK-8000, Aarhus, C, Denmark.

Received: 25 April 2013 Accepted: 20 August 2013

Published: 28 August 2013

\section{References}

1. Compston A, Coles A: Multiple sclerosis. Lancet 2008, 372:1502-1517.

2. Rosati G: The prevalence of multiple sclerosis in the world: an update. Neurological sciences 2001, 22:117-139.

3. Dyment DA, Yee IML, Ebers GC, Sadovnick AD: Multiple sclerosis in stepsiblings: recurrence risk and ascertainment. J Neurol Neurosurg Psychiatry 2006, 77:258-259.

4. Ebers GC, Sadovnick AD, Risch NJ: A genetic basis for familial aggregation in multiple sclerosis. Nature 1995, 377:150-151.

5. Hansen T, Skytthe A, Stenager E, Petersen HC, Brønnum-Hansen H, Kybik KO: Concordance for multiple sclerosis in Danish twins: an update of a nationwide study. Mult Scler 2005, 11:504-510.

6. Svejgaard A: The immunogenetics of multiple sclerosis. Immunogenetics 2008, 60:275-286.

7. Sawcer S, Hellenthal G, Pirinen M, Spencer CCA, Patsopoulos NA, Moutsianas L, Dilthey A, Su Z, Freeman C, Hunt SE, Edkins S, Gray E, Booth DR, Potter SC, Goris A, Band G, Bang Oturai A, Strange A, Saarela J, Bellenguez C, Fontaine B, Gillman M, Hemmer B, Gwilliam R, Zipp F, Jayakumar A, Martin R, Leslie S, Hawkins S, Giannoulatou $E_{\text {, et }}$ al: Genetic risk and a primary role for cell-mediated immune mechanisms in multiple sclerosis. Nature 2011, 476:214-219.

8. Gourraud PA, Harbo HF, Hauser SL, Baranzini SE: The genetics of multiple sclerosis: an up-to-date review. Immunol Rev 2012, 248:87-103.

9. Giovannoni G, Ebers G: Multiple sclerosis: the environment and causation. Curr Opin Neurol 2007, 20:261-268.

10. Kurtzke JF: Epidemiologic evidence for multiple sclerosis as an infection. Clin Microbiol Rev 1993, 6:382-427.

11. Lünemann JD, Kamradt T, Martin R, Münz C: Epstein-barr virus: environmental trigger of multiple sclerosis? J Virol 2007, 81:6777-6784

12. Koprowski H, DeFreitas E, Harper M, Sandberg-Wollheim M, Sheremata W, Robert-Guroff M, Saxinger C, Feinberg M, Wong-Staal F, Gallo R: Multiple sclerosis and human T-cell lymphotropic retroviruses. Nature 1985 , 318:154-160.

13. Pépin M, Vitu C, Russo P, Mornex JF, Peterhans E: Maedi-visna virus infection in sheep: a review. Vet Res 1998, 29:341-367.

14. Gardner M, Kozak C, O'Brien S: The lake Casitas wild mouse: evolving genetic resistance to retroviral disease. Trends Genet 1991, 7:22-27.

15. Clements JE, Mankowski JL, Gama L, Zink MC: The accelerated simian immunodeficiency virus macaque model of human immunodeficiency virus-associated neurological disease: from mechanism to treatment. J Neurovirol 2008, 14:309-317.

16. Grindstaff $P$, Gruener $G$ : The peripheral nervous system complications of HTLV-1 myelopathy (HAM/TSP) syndromes. Semin Neurol 2005, 25:315-327.

17. Cermelli C, Jacobson S: Viruses and multiple sclerosis. Viral Immunol 2000 $13: 255-267$

18. Perron H, Geny C, Laurent A, Mouriquand C, Pellat J, Perret J, Seigneurin JM: Leptomeningeal cell line from multiple sclerosis with reverse transcriptase activity and viral particles. Res Virol 1989, 140:551-561.

19. Blond $J$, Besème F, Duret $L$, Bouton $O$, Bedin F, Perron H, Mandrand B, Mallet F: Molecular characterization and placental expression of HERVW, a new human endogenous retrovirus family. J Virol 1999, 73:1175-1185

20. Antony JM, Deslauriers AM, Bhat RK, Ellestad KK, Power C: Human endogenous retroviruses and multiple sclerosis: innocent bystanders or disease determinants? Biochim Biophys Acta 1812, 2011:162-176.

21. Garcia-Montojo M, Dominguez-Mozo M, Arias-Leal A, Garcia-Martinez Á, De las Heras V, Casanova I, Faucard R, Gehin N, Madeira A, Arroyo R, Curtin F, Alvarez-Lafuente R, Perron H: The DNA copy number of human endogenous retrovirus-W (MSRV-type) is increased in multiple sclerosis patients and is influenced by gender and disease severity. PloS one 2013, 8:e53623.

22. Nexø BA, Christensen T, Frederiksen J, Møller-Larsen A, Oturai AB, Villesen $P$, Hansen B, Nissen KK, Laska MJ, Petersen TS, Bonnesen S, Hedemand A, Wu T, Wang X, Zhang X, Brudek T, Maric R, Søndergaard HB, Sellebjerg F, Brusgaard K, Kjeldbjerg AL, Rasmussen HB, Nielsen AL, Nyegaard M, Petersen T, Børglum AD, Pedersen FS: The etiology of multiple sclerosis: genetic evidence for the involvement of the human endogenous retrovirus HERV-Fc1. PloS ONE 2011, 6:e16652.

23. Hansen B, Oturai AB, Harbo HF, Celius EG, Nissen KK, Laska MJ, Søndergaard $H B$, Petersen $T$, Nexø BA: Genetic association of multiple sclerosis with the marker rs391745 near the endogenous retroviral locus HERV-Fc1: analysis of disease subtypes. PLOS ONE 2011, 6:e26438.

24. Martinelli-Boneschi F, Esposito F, Brambilla P, Lindström E, Lavorgna G, Stankovich J, Rodegher M, Capra R, Ghezzi A, Coniglio G, Colombo B, Sorosina M, Martinelli V, Booth D, Oturai AB, Stewart G, Harbo HF, Kilpatrick TJ, Hillert J, Rubio JP, Abderrahim H, Wojcik J, Comi G: A genome-wide association study in progressive multiple sclerosis. Mult Scler J 2012, 18:1384-1394

25. Laska MJ, Brudek T, Nissen KK, Christensen T, Møller-Larsen A, Petersen T, Nexø BA: Expression of HERV-Fc1, a human endogenous retrovirus, is increased in patients with active multiple sclerosis. J Virol 2012, 86:3713-3722

26. Nissen KK, Laska MJ, Hansen B, Pedersen FS, Nexø BA: No additional copies of HERV-FC1 in the germ line of multiple sclerosis patients. Virol J 2012, 9:1-4.

27. Laska MJ, Nissen KK, Nexø BA: (Some) cellular mechanisms influencing the transcription of human endogenous retrovirus, HERV-Fc1. PloS one 2013, 8:e53895.

28. Strissel PL, Ruebner M, Thiel F, Wachter D, Arif B, Wolf F, Thieme F, Ruprecht K, Matthias W: Reactivation of codogenic endogenous retroviral (ERV) envelope genes in human endometrial carcinoma and prestages: emergence of new molecular targets. Oncotarget 2012, 3:1204-1219.

29. Schulz WA, Steinhoff C, Florl AR: Methylation of endogenous human retroelements in health and disease. Curr Top Microbiol Immunol 2006 310:211-250.

30. Kaiser SM, Malik HS, Emerman M: Restriction of an extinct retrovirus by the human TRIM5alpha antiviral protein. Science 2007, 316:1756-1758.

31. Jouvenet N, Neil SJD, Zhadina M, Zang T, Kratovac Z, Lee Y, McNatt M, Hatziioannou T, Bieniasz PD: Broad-spectrum inhibition of retroviral and filoviral particle release by tetherin. J Virol 2009, 83:1837-1844.

32. Perez-Caballero D, Soll SJ, Bieniasz PD: Evidence for restriction of ancient primate gammaretroviruses by APOBEC3 but not TRIM5alpha proteins. PLOS Pathog 2008, 4:e1000181.

33. Stetson DB, Ko JS, Heidmann T, Medzhitov R: Trex1 prevents cell-intrinsic initiation of autoimmunity. Cell 2008, 134:587-598.

34. Lassmann H, Brück W, Lucchinetti CF: The immunopathology of multiple sclerosis: an overview. Brain Pathol 2007, 17:210-218.

35. Pertel T, Hausmann S, Morger D, Züger S, Guerra J, Lascano J, Reinhard C, Santoni FA, Uchil PD, Chatel L, Bisiaux A, Albert ML, Strambio-De-Castillia C, Mothes W, Pizzato M, Grütter MG, Luban J: TRIM5 is an innate immune sensor for the retrovirus capsid lattice. Nature 2011, 472:361-365.

36. Barber GN: Cytoplasmic DNA innate immune pathways. Immunol Rev 2011, 243:99-108

37. Baum A, García-Sastre A: Induction of type I interferon by RNA viruses: cellular receptors and their substrates. Amino Acids 2010, 38:1283-1299.

38. Rolland A, Jouvin-Marche E, Viret C, Faure M, Perron H, Marche PN: The envelope protein of a human endogenous retrovirus-W family activates innate immunity through CD14/TLR4 and promotes Th1-like responses. J Immunol 2006, 176:7636-7644.

39. Holm CK, Jensen SB, Jakobsen MR, Cheshenko N, Horan KA, Moeller HB, Gonzalez-Dosal R, Rasmussen SB, Christensen MH, Yarovinsky TO, Rixon FJ, Herold BC, Fitzgerald KA, Paludan SR: Virus-cell fusion as a trigger of innate immunity dependent on the adaptor STING. Nat Immunol 2012, 13:737-743.

40. Sharma P, Azebi S, England P, Christensen T, Møller-Larsen A, Petersen T, Batsché E, Muchardt C: Citrullination of histone H3 interferes with HP1mediated transcriptional repression. PLoS genetics 2012, 8:e1002934.

41. Mameli G, Poddighe L, Mei A, Uleri E, Sotgiu S, Serra C, Manetti R, Dolei A: Expression and activation by Epstein Barr virus of human endogenous 
retroviruses-W in blood cells and astrocytes: inference for multiple sclerosis. PloS one 2012, 7:e44991.

42. Maruszak H, Brew BJ, Giovannoni G, Gold J: Could antiretroviral drugs be effective in multiple sclerosis? a case report. Eur J Neurol 2011,

18:e110-e111.

43. Nexø B, Pedersen L, Sørensen H, Koch-Henriksen N: Treatment of HIV and risk of multiple sclerosis. Epidemiology 2013, 24:331-332.

44. Giovannoni G: Raltegravir (Isentress) Pilot Study in Relapsing Multiple Sclerosis (INSPIRE). 2013. http://clinicaltrials.gov/ct2/show/NCT01767701?term = raltegravir + and + multiple + sclerosis\&rank $=1$

45. Curtin F, Lang AB, Perron $H$, Laumonier M, Vidal V, Porchet HC, Hartung HP: GNbAC1, a humanized monoclonal antibody against the envelope protein of multiple sclerosis-associated endogenous retrovirus: a first-inhumans randomized clinical study. Clin Ther 2012, 34:2268-2278.

doi:10.1186/1471-2377-13-111

Cite this article as: Nissen et al:: Endogenous retroviruses and multiple sclerosis-new pieces to the puzzle. BMC Neurology 2013 13:111.

\section{Submit your next manuscript to BioMed Central and take full advantage of:}

- Convenient online submission

- Thorough peer review

- No space constraints or color figure charges

- Immediate publication on acceptance

- Inclusion in PubMed, CAS, Scopus and Google Scholar

- Research which is freely available for redistribution 